\title{
УДК 543.426;546.661;541.49
}

\author{
С. В. Бельтюкова ${ }^{1}$, О. И. Теслюк ${ }^{2}$ Е. О. Ливенцова ${ }^{1}$ \\ ${ }^{1}$ Одесская национальная академия пищевых технологий, кафедра пищевой химии \\ и экспертизы, 65039, г.Одесса, Канатная, 112, e-mail: liventsova.helen@gmail.com \\ ${ }^{2}$ Физико-химический институт им. А.В. Богатского НАН Украины, отдел \\ аналитической химии и физико-химии координационных соединений, 65080, г. \\ Одесса, Люстдорфская дорога, 86, e-mail: olgateslyuk@rambler.ru
}

\section{ЛЮМИНЕСЦЕНТНОЕ ОПРЕДЕЛЕНИЕ ФЕРУЛОВОЙ КИСЛОТЫ В ВИНОГРАДНЫХ ВИНАХ}

\begin{abstract}
Изучены люминесцентные свойства представителя группы оксикоричных кислот - феруловой кислоты (ФК), являющейся маркером качества виноградных вин. Установлено, что в тонком слое сорбента ФК обладает интенсивной собственной люминесценцией, усиленной в присутствии ионов иттрия (III) и неионного поверхностно-активного вещества (ПАВ) Неонол 9-12. Исследовано влияние концентрации ионов иттрия (III), кислотности среды, поверхностно-активных и донорно-активных веществ на интенсивность люминесценции сорбатов комплексов. Найдены оптимальные условия хроматографического выделения феруловой кислоты. В качестве проявляющего предложено использовать раствор хлорида иттрия (III) и ПАВ Неонол 9-12. На основании проведенных исследований разработана методика твердофазного люминесцентного определения феруловой кислоты в винах различных производителей.
\end{abstract}

Ключевые слова: твердофазная люминесценция, иттрий, феруловая кислота.

Феруловая кислота (3-метокси-4-гидроксикоричная кислота) относится к фенолкарбоновым кислотам, а именно к группе оксикоричных кислот [1]. Содержится в семенах многих растений, таких как рис, пшеница, овес, а также кофе, яблоках, артишоках, апельсинах, ананасах, кедровых орехах. Является сильным антиоксидантом. Ее антиоксидантные свойства усиливаются под действием ультрафиолетового облучения, что делает ее ценным компонентом в защитных косметических средствах. Фенолкарбоновые кислоты содержатся также в винах, где играют важную роль в формировании органолептических свойств (букет и вкус), участвуют в биохимических процессах, протекающих при изготовлении и хранении виноградных вин [1]. Знание состава и концентрации присутствующих в винах кислот, в том числе и феруловой, позволяет судить о качестве и правильности технологии приготовления продукта, а также о натуральности виноградных вин [2].

Известны методы определения фенолкарбоновых кислот и идентификации показателей - маркеров качества вина. В настоящее время в качестве маркеров предложены стабильные изотопы [3]. Исследуя соотношение изотопов водорода (дейтерия и протия), углерода $\left({ }^{13} \mathrm{C} /{ }^{12} \mathrm{C}\right)$, кислорода $\left({ }^{18} \mathrm{O} /{ }^{16} \mathrm{O}\right)$ можно выявить возможные фальсификации. Однако это сложный и дорогой метод оценки качества и подлинности вин, требующий применения ядерно-магнитного резонанса или хромато-масс-спектрометрии. Определение обобщенных показателей, таких как массовая концентрация титруемых или летучих кислот [4], не всегда позволяет установить подлинность вина. Идентификацию и количественное определение 
ФК проводят в основном хроматографическими методами, как тонкослойной, так и высокоэффективной жидкостной хроматографии $[1,2,5,6,10]$. Описаны методики хемилюминесцентного определения ФК с использованием проточно-инжекционного анализа $[7,8]$. Предложено определение ФК методом плазменного резонанса с применением наночастиц серебра [9]. Электрохимический сенсор на основе пленки полиглутаминовой кислоты применен для определения ФК в китайской патентованной медицине [11]. В основном, все предлагаемые методики требуют специальной пробоподготовки, длительного времени выполнения и сложного аппаратурного оформления.

Ввиду большого интереса к фенолкарбоновым кислотам, как важным антиоксидантам (АО), обладающим биологической активностью, которые в значительном количестве содержатся в винах и могут служить маркерами их качества и подлинности, разработка простых экспрессных и воспроизводимых методик определения АО в винах представляет собой актуальную задачу. Весьма перспективными являются тест-методы, которые позволяют дать предварительную полуколичественную или количественную оценку присутствия химического компонента в образце, а также провести предварительный скрининг, отбраковку и установление подлинности образца. Это особенно важно в процессе контроля качества вина, которое часто подвергается фальсификации.

Целью настоящей работы являлась разработка методики твердофазного люминесцентного определения феруловой кислоты в винах, основанной на регистрации собственной люминесценции кислоты в тонком слое сорбента, усиленной в присутствии ионов иттрия (III) и неионного поверхностно-активного вещества Неонол 9-12.

Аппаратура и техника эксперимента. В работе использовали стандартные растворы хлорида иттрия $\left(1 \cdot 10^{-2}\right.$ моль/л, 1 мг/мл), которые готовили из соответствующего оксида марки «ОСЧ», путем растворения его в хлористоводородной кислоте (1:1), с последующим удалением ее избытка упариванием. Концентрацию иттрия (III) контролировали комплексонометрическим титрованием раствором комплексона III с индикатором арсеназо I в присутствии уротропина. Стандартные растворы феруловой кислоты («Sigma-Aldrich») (1·10-2 моль/л, 1 мг/мл) и Неонол 9-12 («Sigma-Aldrich») (1·10-2 моль/л) готовили растворением точных навесок в этаноле и дистиллированной воде соответственно. Использовали растворители (бензол, хлороформ, ацетон, метанол, этанол, этилацетат, диоксан), уксусную кислоту и аммиак марки х. ч. Для хроматографирования применяли пластинки для ТCX марки Sorbfil (сорбент силикагель, связывающее вещество - силиказоль, подложка - алюминиевая фольга), Silufol, CTX-1А, фирмы Merck.

Люминесценцию комплекса феруловой кислоты с иттрием регистрировали в области 440-570 нм с помощью спектрометра ИСП-51 с фотоэлектрической приставкой ФЭП-1, а также спектрофлуориметра Fluorolog 3-22 “Horbia Jobin Yvon" (Франция) (безозоновая Хе-лампа 450W).

\section{РЕЗУЛЬТАТЫ И ИХ ОБСУЖДЕНИЕ}

Этанольный раствор феруловой кислоты при облучении УФ-светом ртутной лампы с $\lambda_{\text {макс }}=365$ нм проявляет люминесцентные свойства, однако интенсив- 
ность ее люминесценции невелика. Известно, что I чаях может возрастать при комплексообразовании с ионами металлов, не имеющих собственного поглощения в видимой области спектра. В связи с этим было рассмотрено влияние на I скандия (III), европия (III), тербия (III). Наибольшей интенсивностью люминесценции обладают комплексы с ионами Y(III), который и был выбран для дальнейших исследований. Ионы Y(III) вызывают увеличение $\mathrm{I}_{\text {люм }}$ феруловой кислоты в 3 pasa.

Спектр поглощения феруловой кислоты характеризуется широкой полосой поглощения от 200 нм до 340 нм с максимумами при 215 нм, 292 нм, 318 нм.

Феруловую кислоту из вина выделяли методом тонкослойной хроматографии. С целью выбора оптимальных условий и режимов хроматографирования исследован ряд неподвижных фаз, различающихся по своим свойствам: хроматографические пластинки Silufol, Sorbfil, Merck TLC Aluminium Plates, CTX-1A. Наилучшие результаты достигнуты в случае применения пластинок Merck, на которых изображение пятен ФК было более четким и пригодным для количественного анализа.

В качестве подвижных фаз исследовано несколько систем кислотного характера: бензол-метанол-уксусная кислота (100:50:1), этилацетат-уксусная кислота (95:5), бензол-диоксан-уксусная кислота (90:25:4), n-бутанол-уксусная кислотавода (4:1:2). В качестве оптимальной выбрана система n-бутанол-уксусная кислота-вода (4:1:2). Подвижность ФК при этом составила $\mathrm{R}_{\mathrm{f}}=0,52$.

Изучение влияния объема наносимой на пластинку пробы показало, что наилучший результат достигается при нанесении 2 мкл. При меньших или больших количествах пробы пятна либо очень малы, либо приобретают вытянутую форму. В качестве проявляющего использовали раствор хлорида иттрия (III) и ПАВ Неонол 9-12. Интенсивность люминесценции на пятне хроматограммы зависит от концентрации иона металла. Наибольшая I щем растворе хлорида иттрия (III) с концентрацией $1 \cdot 10^{-2}$ моль/л.

Наибольшая интенсивность люминесценции комплекса ФК с ионами Y (III) наблюдается в растворах при $\mathrm{pH}$ 6,5-6,9. Эта зависимость сохраняется и для твердой фазы, поэтому проявление ФК на пластинках проводили в присутствии 4\%ного раствора уротропина.

Присутствие в проявляющем растворе катионных, анионных, неионогенных поверхностно-активных веществ и поливинилового спирта практически не оказывает влияния на интенсивность люминесценции комплекса Ү(III)-ФК (рис. 1). Наибольшее возрастание I ком комплекса (в 2,5 раза) в фазе сорбента вызывает нейтральное ПАВ Неонол 9-12.

Можно предположить, что в данном случае происходит гидрофобизация и дегидратация комплекса, которая способствует снижению безызлучательных потерь энергии возбуждения за счет гидроксильных связей молекул воды. В результате происходит увеличение интенсивности люминесценции комплекса. Неонол 9-12 был использован в дальнейшем в качестве компонента проявляющего раствора.

Спектр люминесценции феруловой кислоты в фазе сорбента (рис. 2) характеризуется полосой с максимумом при $\lambda_{\text {изл }}=485$ нм, в присутствии иттрия (III) 
$\mathrm{I}_{\text {том }}$ возрастает, однако максимум люминесценции не изменяется. В присутствии Неонол 9-12 сдвиг максимума люминесценции также не наблюдается, увеличивается только $\mathrm{I}_{\text {люм }}$

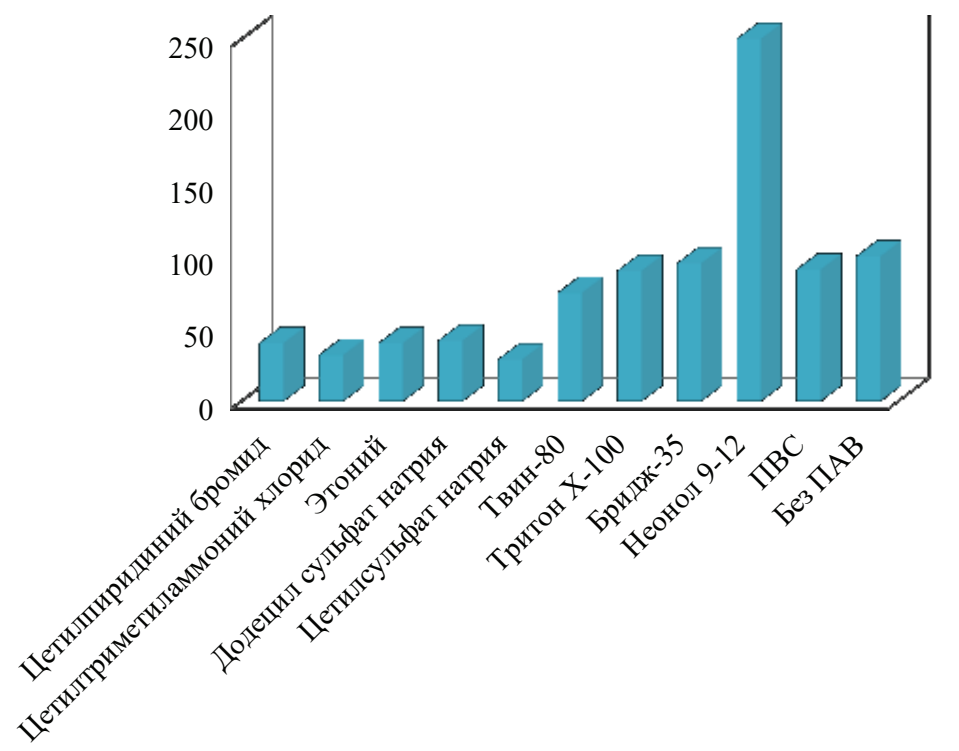

Рис. 1. Влияние поверхностно-активных веществ на интенсивность люминесценции сорбата комплекса Y (III)-ФК; $\mathrm{C}_{\mathrm{Y(III)}}=1 \cdot 10^{-2}$ моль $/$ л, $\lambda_{\text {возб }}=365$ нм.

Fig 1. Effect of surfactants on luminescence intensity of Y(III)-FA complex sorbate;

$$
\mathrm{C}_{\mathrm{Y}(\mathrm{III})}=1 \cdot 10^{-2} \mathrm{~mol} / \mathrm{L}, \lambda_{\mathrm{ex}}=365 \mathrm{~nm} \text {. }
$$

Изучена кинетика затухания люминесценции феруловой кислоты в фазе сорбента. Время жизни возбужденного состояния ФК составляет 221 мкс, в комплексе Y (III)-ФК эта величина увеличивается на $50 \%$ и составляет 300 мкс. В мицеллярной среде Неонол 9-12 время жизни возбужденного состояния комплекса возрастает и составляет 480 мкс, что является подтверждением уменьшения безызлучательных потерь энергии возбуждения.

На основании проведенных исследований разработана методика твердофазного люминесцентного определения феруловой кислоты в винах различных производителей.

\section{Методика определения}

Анализируемую пробу вина предварительно разбавляли этанолом в соотношении 1:10. На линию старта хроматографической пластинки Merck TLC Aluminium Plates наносили микрошприцем 2 мкл исследуемого образца. Параллельно на пластинку наносили стандартный раствор феруловой кислоты, содержащий $2 \cdot 10^{-7}$ $1 \cdot 10^{-4}$ мг/л ФК в зависимости от предполагаемого содержания в пробе. Пластинку подсушивали и помещали в хроматографическую камеру в подвижную фазу (смесь 


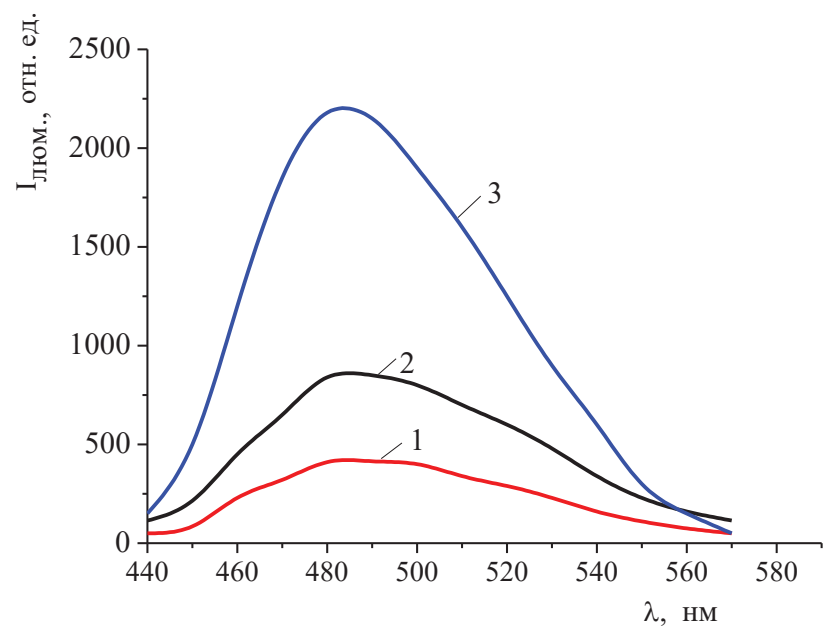

Рис. 2. Спектры люминесценции сорбатов ФК (1) в присутствии Y(III) (2) в мицеллярной среде Неонол 9-12 (3); $\mathrm{C}_{\mathrm{Y(III)}}=1 \cdot 10^{-2}$ моль/л, $\mathrm{C}_{\text {Неонол 9-12 }}=5 \cdot 10^{-5}$ моль/л, $\lambda_{\text {возб }}=365 \mathrm{HM}$.

Fig. 2. Luminescence spectra of sorbates of FA (1) in presence of $Y$ (III) (2) in micellar medium Neonol 9-12 (3); $\mathrm{C}_{\mathrm{Y}(\mathrm{III})}=1 \cdot 10^{-2} \mathrm{~mol} / \mathrm{L}, \mathrm{C}_{\mathrm{Neonol} 9-12}=5 \cdot 10^{-5} \mathrm{~mol} / \mathrm{L}, \lambda_{\mathrm{ex}}=365 \mathrm{~nm}$.

растворителей n-бутанол-уксусная кислота-вода (4:1:2)). Хроматографирование проводили восходящим способом. При достижении линии фронта растворителей, пластинку извлекали из камеры. Полученную хроматограмму высушивали в сушильном шкафу при температуре $40^{\circ} \mathrm{C}$ в течение 2 минут или на воздухе при комнатной температуре в течение 10 минут. Идентификацию ФК проводили по стандартному образцу вещества-свидетеля. Для проявления пятен феруловой кислоты пластинку равномерно и последовательно обрабатывали раствором хлорида Y(III) с концентрацией $1 \cdot 10^{-2}$ моль/л, Неонол 9-12 с концентрацией 5·10-5 моль/л и 4 \%-ным раствором уротропина. Идентификацию ФК на пластинке проводили по появлению люминесценции пятна ФК в УФ свете с $\lambda_{\text {возб }}=365$ нм визуально сравнивая $\mathrm{I}_{\text {люм }}$ пробы и стандарта. Проявленные пятна, соответствующие феруловой кислоте $(\mathrm{Rf}=0,52)$, вырезали из пластинки и регистрировали $\mathrm{I}_{\text {люм }}$ при $\lambda_{\text {нзучч }}=485 \mathrm{Hм}$. Количественное определение ФК проводили по градуировочному графику, построение которого выполняли следующим образом. На пластинку наносили различные количества стандартного раствора ФК и проводили хроматографирование и проявление хроматограммы, как описано выше. Затем из пластинки вырезали пятна с ФК, помещали в кювету для твердых образцов и измеряли интенсивность люминесценции при $\lambda_{\text {излчч }}=485$ нм. По полученным данным строили градуировочный график, откладывая на оси абсцисс концентрацию ФК, а на оси ординат значение интенсивности люминесценции. Предел обнаружения феруловой кислоты составляет 0,03 мкг/мл.

Результаты определения феруловой кислоты методом добавок в винах разных производителей приведены в таблице. 
Результаты определения феруловой кислоти в винах

Results of ferulic acid determination in wines

\begin{tabular}{|l|c|c|c|c|}
\hline \multicolumn{1}{|c|}{ Объект анализа } & $\begin{array}{c}\text { Введено } \\
\text { мг/л }\end{array}$ & $\begin{array}{c}\text { Найдено в пробе } \\
\text { с добавкой } \\
\text { мг/л }\end{array}$ & $\begin{array}{c}\text { Найдено в пробе } \\
\text { мг/л }\end{array}$ & $\mathbf{S}_{\mathbf{r}}$ \% \\
\hline $\begin{array}{l}\text { Вино Киндзмараули, } \\
\text { Тов. «Братья Асканели», } \\
\text { Грузия }\end{array}$ & 0,5 & $3,93 \pm 0,06$ & 3,43 & 5,2 \\
\cline { 2 - 5 } & 1,0 & $4,43 \pm 0,08$ & 3,43 & 6,5 \\
\hline $\begin{array}{l}\text { Вино «Ашан» } \\
\text { «Лопез Моренас» Испания }\end{array}$ & 0,5 & $1,11 \pm 0,03$ & 0,61 & 5,3 \\
\hline $\begin{array}{l}\text { Сухое красное вино «Мер- } \\
\text { ло» ТМ «Французский }\end{array}$ & 0,5 & $1,62 \pm 0,06$ & 0,62 & 6,9 \\
\cline { 2 - 5 } бульвар», Украина & 1,0 & $0,90 \pm 0,02$ & 0,40 & 7,8 \\
\hline \multirow{2}{*}{$\begin{array}{l}\text { «Кагор» } \\
\text { ТМ «Вина Комрата», Мол- }\end{array}$} & 0,5 & $1,40 \pm 0,06$ & 2,25 & 5,6 \\
\cline { 2 - 5 } & 1,0 & $2,75 \pm 0,06$ & 2,26 & 4,8 \\
\hline
\end{tabular}

Предлагаемая методика определения ФК в винах характеризуется удовлетворительными метрологическими характеристиками и простотой выполнения. При $\mathrm{n}=5, \mathrm{P}=0,95$ величины относительного стандартного отклонения $\mathrm{Sr}$ составляет $4,5-7,8 \%$.

\section{ВЫВОДЫ}

Изучены люминесцентные свойства феруловой кислоты, являющейся маркером качества виноградных вин. Установлено, что в тонком слое сорбента ФК обладает интенсивной собственной люминесценцией, усиленной в присутствии ионов иттрия (III) и неионного поверхностно-активного вещества Неонол 9-12. На основании проведенных исследований разработана методика твердофазного люминесцентного определения феруловой кислоты в винах различных производителей.

\section{СПИСОК ЛИТЕРАТУРЫ}

1. Положишникова М.А., Перелигин О.Н. Определение биологической ценности и идентификация красных виноградных вин по содержанию флавонолов и фенолкарбоновых кислот.// Виноделие и виноградарство. - 2005. - № 6. - С. 22-23.

2. Бежуашвили М.Г., Месхи М.Н., Бостоганашвили М.В., Маланмя М.А. Антиоксидантная активность виноматериалов для вин кахетинского типа // Виноделие и виноградарство. - 2005. - № 6. - С. 28-29.

3. Оганесяни Л.А., Панасюк А.Л., Кузьмина Е.И., Песчанская В.А., Харламова Л.Н. Определение подлинности коньяков на основе установления природы спирта // Виноделие и виноградарство. $-2012 .-$ № $2 .-$ C. $14-15$.

4. Селиверстова И.В., Иванов А.А., Северов В.В. Ионоэксклюзионное определение оксикоричных и оксибензойных кислот в виноградных винах // Вестн. Моск. ун-та. - 2004. - Т. 45, №1. - С. 47-50.

5. Saygi K. Determination of Some Phenolic Compounds from Commercial Wine Vinegar Samples in Turkey by High Performance Liquid Chromatography. // J. New Res. Sci. -2017.-Vol. 6, N 2. - P. 41-46.

6. Ertan Anh R., Vural N., Kizilet E. An Alternative Method for the Determination of Some of the Antioxidant Phenolics in Varietal Turkish Red Wines. // J. Inst. Brew. - 2008. - Vol. 114, N 3. - P. 239-245. 
7. Wang J.P., Li N.B., Luo H.Q. Chemiluminescence determination of ferulic acid by flow-injection analysis using cerium(IV) sensitized by rhodamine 6G. // Spectrochim. Acta Mol. Biomol. Spectrosc. - 2008. - Vol. 71, N 1. - P. 204-208.

8. Li L.N., Li N.B., Luo H.Q. Permanganate-based chemiluminescence analysis of ferulic acid using flow injection. // Anal Sci. - 2005. - Vol. 21, N 8. - P. 963-966.

9. Wang H.Y., Li Y.F., Huang C.Z. Detection of ferulic acid based on the plasmon resonance light scattering of silver nanoparticles // Talanta. - 2007. - Vol. 72, N. - P. 1698-1703.

10. Стасевич O.В., Лихтарович Е.С., Шемет С.Н. Анализ феруловой кислоты в растениях, содержащих фенилпропаноиды. // Труды БГТУ. - 2014. - № 4. - С. 200-203.

11. Ван С.Г., Ли Дж., Фан Я-Дж, Жан С. Определение феруловой кислоты в китайской патентованной медицине с помощью сенсора на основе пленки полиглутаминовой кислоты // Электрохим. - 2012. - Т. 48, № 12. - C. 1272-1279.

Стаття надійшла до редакції 24.06.2019

\section{С. В. Бельтюкова ${ }^{1}$, О. І. Теслюк ${ }^{2}$ О. О. Лівенцова ${ }^{1}$}

${ }^{1}$ Одесская національна академія харчових технологій, кафедра харчової хімії та експертизи, 65039, м.Одеса, Канатна, 112, e-mail: liventsova.helen@gmail.com ${ }^{2}$ Фізіко-хімічний інститут ім. А.В. Богатського НАН України, відділ аналітичної хімії та фізико-хімії координаційних сполук, 65080, м. Одеса, Люстдорфська дорога, 86, e-mail: olgateslyuk@rambler.ru

\section{ЛЮМІНЕСЦЕНТНЕ ВИЗНАЧЕННЯ ФЕРУЛОВУЇ КИСЛОТИ У ВИНОГРАДНИХ ВИНАХ}

Вивчено люмінесцентні властивості представника групи оксікорічних кислот ферулової кислоти (ФК), яка є маркером якості виноградних вин. Встановлено, що в тонкому шарі сорбенту ФК має інтенсивну власну люмінесценцію, посилену в присутності іонів ітрію (III) і неіонної поверхнево-активної речовини (ПАР) Неонол 9-12. Знайдено оптимальні умови комплексоутворення сорбату. Досліджено вплив концентрації іонів ітрію (III), кислотності середовища, поверхнево-активних і донорно-активних речовин на люмінесцентні властивості сорбату комплексу. Встановлено, що максимальне збільшення інтенсивності люмінесценції комплексу (в 2,5 рази) у фазі сорбенту досягається в міцелярному середовищі Neonol 9-12. 3 метою вибору оптимальних умов і режимів хроматографування досліджений ряд нерухомих фаз, які розрізняються за своїми властивостями (Silufol - UV 254, Sorbfil - UV 254, Merck TLC Aluminium Plates, CTX-1A). Найкращим виявилося застосування хроматографічних пластинок марки Merck TLC Aluminium Plates, на яких зображення плям ФК було більш чітким і придатним для кількісного аналізу. У якості рухомої фази була обрана система n-бутанол-оцтова кислота-вода (4:1:2). Як проявляючий запропоновано використовувати розчин хлориду ітрію (III) і ПАР Неонол 9-12. Для досягнення оптимального значення $\mathrm{pH}(6,5-6,9)$ використовували 4\% водний розчин уротропіну. Коефіцієнт відгуку ФК в цих умовах становить $\mathrm{R}_{\mathrm{f}}=0,52$. На підставі проведених досліджень розроблена методика твердофазного люмінесцентного визначення феруловой кислоти в винах різних виробників. Вміст ФК у винах визначали за градуїрувальним графіком, при цьому реєстрували $\mathrm{I}_{\text {lum }}$ сорбатів комплексів ітрію (III) хлориду з ФК при $\lambda=485$ нм $\left(\lambda_{\text {збуд }}=365\right.$ нм). Правильність отриманих результатів перевіряли методом «введенознайдено». Запропонована методика визначення ФК характеризується задовільними метрологічними характеристиками і простотою виконання. Відносне стандартне відхилення становить (Sr) 4,5 - 7,8\%. Межа виявлення ФК становить 0,03 мкг/мл.

Ключові слова: твердофазна люмінесценція, ітрій, ферулова кислота. 


\section{S. V. Beltyukova ${ }^{1}$, O. I. Teslyuk ${ }^{2}$, E. O. Liventsova ${ }^{1}$}

${ }^{1}$ Odessa National Academy of Food Technologies, Department of Food Chemistry and Expertise, 65039, Odessa, Kanatnaya str, 112, Ukraine, e-mail: liventsova.helen@gmail.com

${ }^{2}$ A.V. Bogatsky Physico-Chemical Institute,National Academy of Sciences of Ukraine, Department of Analytical Chemistry and Physical Chemistry of Coordination Compounds, Lustdorfskaya road, 86, Odessa, 65080, Ukraine, e-mail: olgateslyuk@rambler.ru

\section{LUMINESCENT DETERMINATION OF FERULIC ACID IN GRAPES WINE}

The luminescent properties of important phenolic compounds - ferulic acid (FA), which is a quality marker of grape wines, were studied. It has been established that in thin layer of sorbent, FA has an intense intrinsic luminescence enhanced in the presence of yttrium (III) ions and a non-ionic surfactant Neonol 9-12. Optimal conditions for the sorbate complexation were found. The influence of yttrium (III) chloride ions concentration in solution, the acidity of the medium, surface-active and donor-active substances on the luminescence intensity of the sorbates complexes were studied. The maximum increase of $I_{1 \mathrm{~mm}}$ complex ( 2.5 times) in phase of sorbent is achieved in the micellar medium surfactant Neonol 9-12. The optimal conditions for chromatographic isolation of ferulic acid were found. The maximum increase of luminescence intensity was obtained on chromatographic plate Merck TLC Aluminum Plates. The n-butanol-acetic acid-water system (4: 1:2) was chosen as the mobile phase. The yttrium (III) chloride in presence surfactant Neonol 9-12 was proposed as an enhanced solution. A $4 \%$ aqueous hexamine solution was used to achieve the optimal $\mathrm{pH}$ value $(6,5-6,9)$. The response factor of $\mathrm{FA}$ in this conditions was $\mathrm{Rf}=0.52$. The method of solid-phase luminescent determination of ferulic acid in wines of different manufacturers has been developed on the base of conducted research. FA content in wines were determined as per calibration curve, while registering $\mathrm{I}_{\text {lum. }}$ of sorbates complexes yttrium (III) chloride with FA at $\lambda=485 \mathrm{~nm}\left(\lambda_{\text {exit }}\right.$ $=365 \mathrm{~nm}$ ). Correctness of results obtained was checked by the "entered-found" method. The determination accuracy and reliability was verified by statistical processing of the findings obtained. The relative standard deviation is $\left(\mathrm{S}_{\mathrm{r}}\right) 4,5-7,8 \%$. The FA detection limit was 0.03 $\mu \mathrm{g} / \mathrm{ml}$.

Key words: solid-phase luminescence, yttrium, ferulic acid.

\section{REFERENCES}

1. Polozhishnikova M.A., Pereligin O.N. Opredeleniye biologicheskoy tsennosti i identifikatsiya krasnykh vinogradnykh vin po soderzhaniyu flavonolov i fenolkarbonovykh kislot. Vinodeliye i vinogradarstvo, 2005, no 6, pp. 22-23. (in Russian)

2. Bezhuashvili M.G., Meskhi M.N., Bostoganashvili M.V., Malanmya M.A. Antioksidantnaya aktivnost'vinomaterialov dlya vin kakhetinskogo tipa. Vinodeliye i vinogradarstvo, 2005, no 6, pp. 28-29. (in Russian)

3. Oganesyants L.A., Panasyuk A.L., Kuz'mina Ye.I., Peschanskaya V.A., Kharlamova L.N. Opredeleniye podlinnosti kon'yakov na osnove prirodnykh spirtov. Vinodeliye i vinogradarstvo, 2012, no 2, pp. 14-15. (in Russian)

4. Seliverstova I.V., Ivanov A.A., Severov V.V. Ionoeksklyuzionnoye opredeleniye oksikorichnykh i oksibenzoynykh kislot v vinogradnykh vinakh. Vestn. Mosk. Un-ta, 2004, vol. 45, no 1, pp. 47-50. (in Russian)

5. Saygi K. Determination of Some Phenolic Compounds from Commercial Wine Vinegar Samples in Turkey by High Performance Liquid Chromatography. J. New Res. Sci., 2017, vol. 6, no 2, pp. 41-46.

6. Ertan Anh R., Vural N., Kizilet E. An Alternative Method for the Determination of Some of the Antioxidant Phenolics in Varietal Turkish Red Wines. J. Inst. Brew, 2008, vol. 114, no 3, pp. 239-245. http://doi. org.10.1002/j.2050-0416.2008.tb00334.x 
7. Wang J.P., Li N.B., Luo H.Q. Chemiluminescence determination of ferulic acid by flow-injection analysis using cerium(IV) sensitized by rhodamine 6G. Spectrochim. Acta Mol. Biomol. Spectrosc., 2008, vol. 71, no 1, pp. 204-208. http://doi.org.10.1016/j.saa.2007.12.005.

8. Li L.N., Li N.B., Luo H.Q. Permanganate-based chemiluminescence analysis of ferulic acid using flow injection. Anal Sci. 2005, vol.21, no 8, pp. 963-966.

9. Wang H.Y., Li Y.F., Huang C.Z. Detection of ferulic acid based on the plasmon resonance light scattering of silver nanoparticles. Talanta. 2007, vol 72, N 5, pp. 1698-1703. http://doi.org.10.1016/j.talanta.2007.02.028.

10. Stasevich O.V., Likhtarovich Ye.S., Shemet S.N. Pri analize ferulovoy kisloty v rasteniyakh byli polucheny fenilpropanoidy. Trudy BGTU. 2014, no 4, pp. 200-203. (in Russian)

11. Van S.G., Li Dzh., Fan YA-Dzh., Zhan S. Opredeleniye ferulovoy kisloty v zapatentovannom kitayskom lekarstvennom sredstve s ispol'zovaniyem plenochnogo sensora poliglutaminovoy kisloty. Elektrokhim., 2012, vol. 48, no 12, pp. 1272-1279. (in Russian) 